\title{
Study of some immunological effects of methotrexate in people with rheumatoid arthritis
}

\author{
Faten kareema \& Wijdan Thamer ${ }^{b}$
}

\author{
a College of Science ,University of Al-Qadisiyah ,Email:fateenn821@ gmail.com. \\ a College of Science ,University of Al-Qadisiyah ,Email:swmn1999@gmali.com
}

\begin{abstract}
The aim of this study was to determine the effect of rheumatoid arthritis on some immunological criteria in women with rheumatoid arthritis at $\mathrm{M}$

arjan Specialist Hospital in Babil governate for the period from 20/10/2018 until 20/4/2019, when 90 samples of women aged between 25 to 55 years old into three groups: the first (30) women with rheumatoid arthritis Calming treatments. And the second (30) of women with rheumatoid arthritis who received methotrexate treatment. The third sample (30) included a sample of nonRA patients representing control.

$5 \mathrm{~mL}$ of venous blood was withdrawn and placed in a test tube and then placed in a centrifuge to separate the serum and perfor $\mathrm{m}$ immunological tests (Inter Lockin 4, Inter Lockin 6)

Results showed a significant increase of $\mathrm{P}<0.0 .5$ in the level of interleukin (4.6) in infected women compared to the control group.

We conclude from the study that the incidence of rheumatoid arthritis had a significant effect on the level of interleukins (6.4) in women, and was the highest difference in the group of women who use analgesics as a treatment.

The study showed that MTX had a significant effect in reducing measured parameter levels compared to control group
\end{abstract}

\section{KEYWORDS}

Rheumatoid arthritis ,Interleukin

\section{Introduction: -}

Arthritis is a common disease at present, a serious disease that develops rapidly and takes a variety of forms and can occur at any age for both sexes (Puttick, 2001). "This disease causes inflammation, pain and stiffness of various joints in the body, and leads to the movement stop of the patient to have a significant impact on the activities of the person who affects $75 \%$ of women (Lehtonen et al., 1994).

There are different types of arthritis including rheumatoid arthritis, psoriatic arthritis, osteoporosis, juvenile arthritis and acute arthritis (Bird et al., 2006)

Rheumatoid arthritis: Is an autoimmune disorder in the immune system that produces non-specialized antibodies that attack various organs of the body leading to inflammation of the synovial tissue around the joint and swollen (hypertrophy) of the cell and increases in the synovial fluid and urges the development of fibrous tissue in the synovial membrane and thus lead to the disease to damage the cartilage Hinge (Brink et al., 2015).

Rheumatoid arthritis is defined as multiple articular inflammation, which affects several joints and is similar to small joints. Hand and foot, which affect joints in the body and lead to arthritis, lead to functional disability of the patient who poses a risk to his life (Cohndo lara, 2006)

Rheumatoid arthritis affects about $2-1 \%$ of the population depending on the geographical distribution of the world (Arthritis foundation Malaysia, 2012). Several studies in different countries have shown the prevalence of rheumatoid arthritis (RA) in large disparities among different populations, with a prevalence of $0.5-1 \%$ in Northern Europe and North America with an annual incidence of 20-50 new cases per $1,000,000$ population (Alamanos and drosos) , 2005)

In Iraq, its prevalence was $1 \%$, which is similar to its prevalence in Europe and North America. The percentage observed in females to males is 1-3 (Al-Rawi et al., 1999) Rheumatoid arthritis patients use different types of treatments, DMARDS help reduce and relieve pain, inflammation and non-steroidal anti-inflammatory drugs (NSADS) and include a range of treatments used

In the treatment of rheumatism, including Leflunomide, Sulfasalazine, hydroxychloroquin Glucocorticoids and Methotrxate (MTX), MTX is used extensively and even in the early stages of the disease and is the first treatment in the treatment of rheumatism, for the benefit of treatment compared with other treatments (de Jong et al. , 2016) Objective of the study: 
In light of the above, the study was designed to determine the immunological effects caused by the use of MTX treatment in comparison with the analgesic treatments in patients with rheumatoid arthritis and the damage resulting from the use of this treatment. The criteria for achieving the study objectives Determination of the concentration of interleukins (Interloukin 4, Interloukin

\section{Materials and methods}

2.1-Design of the study

The study was conducted at the Medical Rehabilitation and Physiotherapy Center at Marjan Specialist Hospital, Babil Governorate for the period from 20/10/2018 to 20/4/2019. The study included the follow-up of 90 cases of women with rheumatoid arthritis diagnosed by the Specialized Rheumatoid Arthritis Committee Morjan after the confirmation of their health and they do not suffer from diseases of blood pressure, sugar and the group of healthy The sample of the study was divided into two groups:

The first group of patients: - included 60 cases of women with rheumatoid arthritis, aged between 25 and 55 years. This group was divided according to the type of treatment:

* The first group: the group of patients who take various analgesic treatments and included 30 women

* The second group: the group of patients taking methotrexate therapy (MTX) with 4 tablets per week, equivalent to $10 \mathrm{mg}$ and included 30 women

The second group of healthy people: - included 30 samples of women who did not suffer from any disease and have ranged in age from 25-55 years have been confirmed safety through the examination of the rheumatic factor RF as well as have been immunological tests for them

2- Interleukin-4 and interleukin-6 (IL-4) and IL-6

Serum Interleukins were measured to measure inflammation of RA patients using several analyzes prepared by Elabscience.

3-The statistical program ( $\mathrm{R}$ program) was used to analyze the results by means of standard. ( $\mathrm{SD} \pm$ Mean ) The ANOVA test was also used to analyze differences between major groups. , Below a significant level of $p<0.05$ (Faraway, 2002).

\section{Results and discussion:-}

3.1 Effect of disease severity and treatment in some immunological standards for women with rheumatoid arthritis.

\subsubsection{Measurement of the level of interleukin 4}

The results in Table 2-4 and Figure 1-4 showed a significant increase in $\mathrm{P}<0.05$ ) in the interleukin- 4 concentration (IL-4) for women with Group A rheumatoid arthritis who took various types of analgesics $(125.42 \pm 125.7)$ and Group B group Women taking methotrexate (MTX) $(849.5 \pm 105.12)$ control group $(312.4 \pm 12.20)$. When comparing the groups between them, group $\mathrm{A}$ and those taking the analgesics showed the highest difference of $\mathrm{P}<0.05$ with group $\mathrm{B}$ and control.

Table (1) Effect of severity of infection by treatment type in the efficacy of interleukin 4 and interleukin 6.

\begin{tabular}{|c|c|c|c|}
\hline \multicolumn{2}{|c|}{ mean \pm S.D } & \multirow{2}{*}{ Groups } \\
\hline Control & Group B & Group A & IL-4 \\
\hline $312.4 \pm 12.20 \mathrm{c}$ & $\mathbf{8 4 9 . 5} \pm \mathbf{1 0 5 . 1 2} \mathbf{b}$ & $\mathbf{1 2 5 7 \pm 1 2 2 . 4 2} \mathbf{a}$ & IL-6 \\
\hline $\mathbf{2 2 9 . 1 \pm 2 1 . 2 8} \mathrm{c}$ & $\mathbf{4 8 1 . 9 \pm 6 4 . 6 8 ~ b}$ & $\mathbf{7 6 6 . 9} \pm \mathbf{7 6 . 6 7}$ a & \\
\hline
\end{tabular}

- The different small letters a, $b, c$ means that there is a significant difference $(p<0.05)$ between the groups.

-Group A is a group of women with rheumatoid arthritis who take palliative treatments.

-Group B is the group of women with rheumatoid arthritis who take methotrexate therapy

- Control control group 


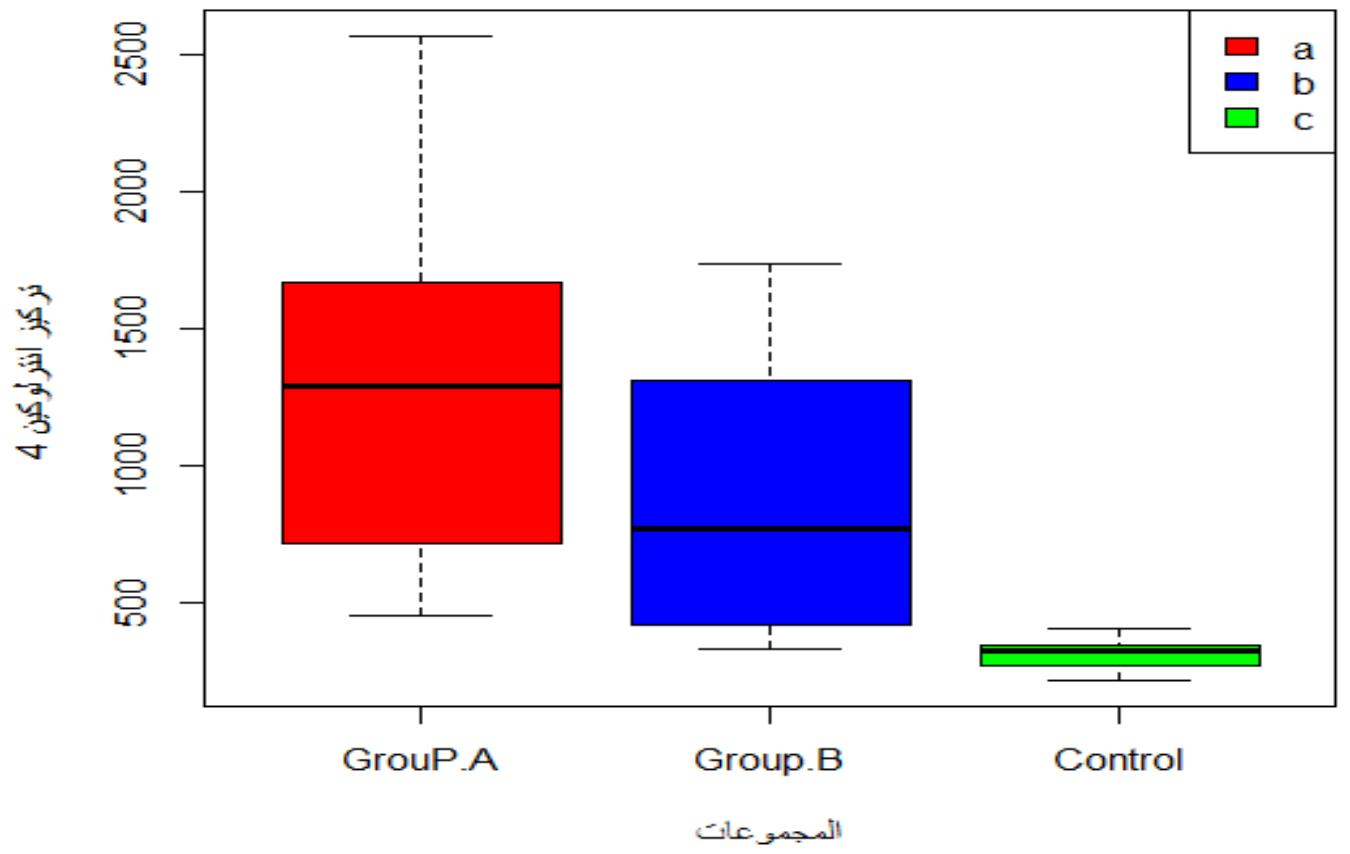

Figure (1) Effect of rheumatoid arthritis in the concentration of interleukin 4 (pg / ml)

- The different small letters $a, b, c$ means that there is a significant difference $(p<0.05)$ between the groups.

-Group A is a group of women with rheumatoid arthritis who take palliative treatments.

-Group B is the group of women with rheumatoid arthritis who take methotrexate therapy

- Control control group

- The clear line in the diagram refers to the arithmetic mean

In his study, Karim and others showed a high concentration of interleukin 4A, indicating the extent of inflammation of the synovial tissue of the joint. IL-4 is a multifunctional cell that helps to grow cells and is considered an anti-inflammatory medium (Karim et al., 2005).

Studies have shown that IL-4 has effects on the Th1 / Th2 balance, which may have roles in the regulation of autoimmune diseases, as Th2 regulates cell proliferation and apoptosis and the expression of many genes in different cell

\subsection{Measuring the level of interleukin 6}

The results in Table 2-4 and Figure 1-4 showed a significant increase in $\mathrm{P}<0.05$ ) in the interleukin- 6 concentration (IL-6) for women with Group A rheumatoid arthritis who took various types of analgesics (766.9 \pm 76.67) and Group B types, including epithelial and pancreatic cells, (Elpek et al., 2007).

IL-4 may be due to other diseases, including asthma, as well as idiopathic pulmonary fibrosis (ILD) in patients with rheumatoid arthritis. The Shen study shows that rheumatoid patients with ILD have high levels of IL-4, In the body's attempt to stop the abnormal response (Shen et al., 2013).

group Women taking methotrexate (MTX) $(481.9 \pm 64.68)$ control group $(229.1 \pm 21.28)$. When comparing the groups between them, group $\mathrm{A}$ and those taking the analgesics showed the highest difference of $\mathrm{P}<0.05$ with group $\mathrm{B}$ and control. 


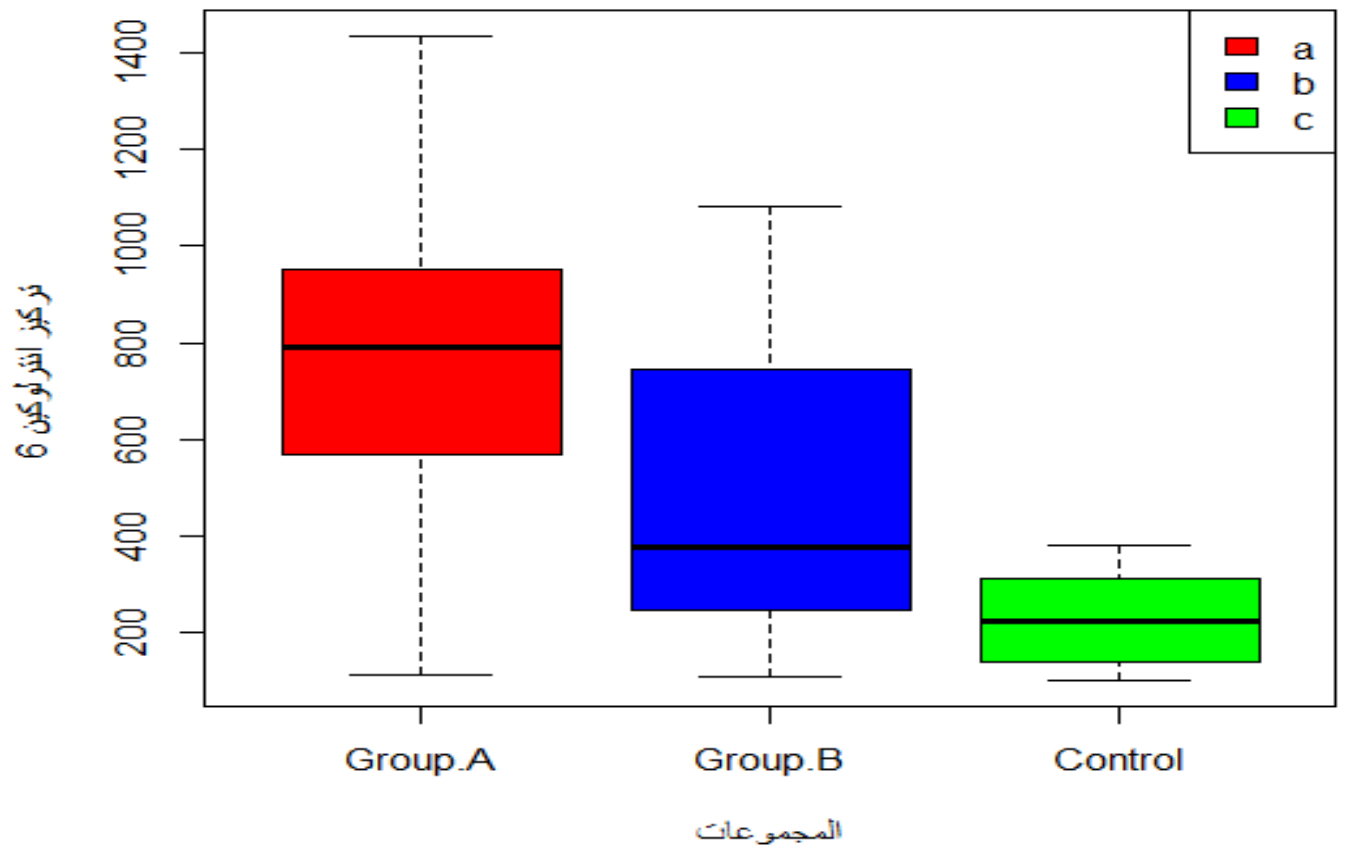

Figure (2) Effect of rheumatoid arthritis in the concentration of interleukin 6 (pg / ml) ..

- The different small letters a, b, c means that there is a significant difference $(\mathrm{p}<0.05)$ between the groups.

- Group A is a group of women with rheumatoid arthritis who take palliative treatments.

- Group B is the group of women with rheumatoid arthritis who take methotrexate therapy

- Control control group

- The clear line in the diagram refers to the arithmetic mean

In the results of his study in 2013, AL-Salih explained that the high level of the concentration of IL- 6 in serum and synovial fluid taken from joints affected by rheumatoid arthritis may explain the emergence of inflammatory factors such as CRP and TNF_ $\alpha$ through uncontrolled IL-6 hyperplasia in these patients.

Peter explained in his 2003 study that the large production of interleukin 6 in the affected joint by large macrophage cells plays a major role in the development of rheumatoid arthritis, increased severity of inflammation and joint destruction, and the restoration of damaged tissue and is consistent with (Falah ,2009).

IL-6 is an inflammatory cytokine that causes inflammation in patients with rheumatoid arthritis and causes joint damage and results of IL-6 concentration similar to that of (EL-Safri ,2008).

In his study in 2017, he found that the rise of leptin in people with rheumatoid arthritis in synovial fluid or in serum increases IL-6, which acts here as an inflammatory cellular motor and increases the progression of disease (Misato and masahiko, 2011) .
IL-6 is known as cytokine, which acts as a factor that drives the final maturity of B cells to plasma cells and participates in many biological processes such as inhibition of $\mathrm{T}$ cells and induction of acute phase response (Chog \& panahi, 2001).

Other studies have suggested that IL-6 may play a role as a factor in genetic susceptibility to RA (Study, 2014).

\section{Conclusions}

Low level (IL-4-IL-6) in patients treated with MTX This indicates the role of treatment in reducing the rate of inflammation.

2. Low fat levels in patients treated with MTX compared with users of analgesics. This refers to the role of therapy in improving kidney and liver function.

The results showed that patients treated with analgesics were more likely to have complications than patients using MTX. 
Al - Rawi, Z.S.; Al - Shacharchi, H.A. and Marijana ,N.H Alamanos, Y. and Drosos,A.A.(2005). Epidemiology of adul rheumatoid arthritis. Autoimmunity Reviews,4: 130- 136.

Al - Rawi, Z.S.; Al - Shacharchi, H.A. and Marijana ,N.H ( 1999). Rheumatoid arthritis in Iraq .; Ann Rheum ;16: 128-132.

AL-salih,m.w.m\& salman,A,N.(2013).Evaluation of heat shock protein 70 (Hsp70) and some immunologic makers of Rheumatoid Arthritis patients in thi-Qar province/south of Iraq .University of thi -Qar /science in Biology.

Arthritis Foundation Malaysia (2012). website at http://www.afm. org.my. Last assessed on 23 July 2012.

Bird, H.; Green, C.; Hamer, A.; Hammond, A.; Harkess, J.; Hurley, M.; Jefferson, P.; Pattison, D.; Sooctt, D. L. and Dore, R.K. (2006).Arthritis. 1st ed., DK Publishing, Inc., 375 Hudson Street, New York.

Brink,M.,Verheul,M.K.,

Ronnelid, J., Berglin,E.,Holmdahl,R.,Toes, R.E., Klareskog,L.,Trouw,L.A.\&RantapaaDahlqvist, S.(2015).Anticarbamylated protein antibodies in the pre-symptomatic phase of multiple anticitrulline rheumatoid arthritis, their relationship with.

Cohnde lara (2006) .Rumatologie /orthopédie traumalogie Arnett, FC., Edworthy, SM., Bloch DA et al. The American Rheumatism Association 1987 revised criteria for the classification of rheumatoid arthritis. Arthritis and Rheum.31 (3), 315-324.

Choy ,E.H. and Panayi, G.S.(2001). Cytokine pathways and joint inflammation in rheumatoid arthritis. N Engl J Med;344:90716.

De Jong PH, Hazes JM, Buisman LR, (2016). Best costeffectiveness and worker productivity with initial triple DMARD therapy compared with methotrexate monotherapy in early rheumatoid arthritis: cost-utility analysis of the tREACH trial. Rheumatology (Oxford).
Elpek, K.G., E.S. Yolcu, D.D. Franke, C. Lacelle, R.H. Schabowsky, H. Shirwan, (2007). Ex vivo expansion of CD4+CD25+FoxP3+ T regulatory cells based on synergy between IL-2 and 4-1BB signaling. J Immunol, 179: 7295-304 .

El-Saffar , J.M. (2008). Role of anti-cyclic citrullinated peptide antibodies and interleukins 2,6 in diagnosis of rheumatoid arthritis in Iraq patients. Ph.D. thesis. College of science. University of Baghdad

Faraway, J. J. (2002). Practical Regression and Anova using R, (July).

Falah. Manhal. (2009)Cytokine ProfileinPatients with Rheumatoid Arthritis. Fac Med Baghdad; Vol. 51, No. 4.

Karim, R., Francesco, F.; John, C. S; Emma J. R., Chi Y. L. ,Arne, N. A.; Janet, M. L.; Caroline, G.; Christopher, D. B. and Mike, S. (2005). Early rheumatoid arthritis is characterized by a distinct and transient synovial fluid cytokine profile of $\mathrm{T}$ cell and stromal cell origin. Arthritis Research \& Therapy, 7(4): 784-795.

Lehtonen, L.; Kortekanngas, P.; Oksmon, P.; Eeola, E.; Aro, H. \& Toivanen ,A.(1994).Synovial fluid Muramic Acid in Acute inflammatory Arithritis. British J. Rheumatol. 33(12):1127-1130.

Murakami, M., Y. Okuyama, H. Ogura, S. Asano, Y. Arima, M. Tsuruoka,( 2011). Local microbleeding facilitates IL6- and IL-17-dependent arthritis in the absence of tissue antigen recognition by activated T cells. J Exp Med, 208: 103-14.

Misato Hashizume and Masahiko Mihara ,(2011).The Roles of Interleukin-6 in the Pathogenesis of Rheumatoid Arthritis. Hindawi Publishing Corporation Arthritis. Article ID 765624, 8 pages

Peter K. K. Wong, Ian K. Campbell, Paul J. Egan, Matthias Ernst, and lan P.(2003) Wicks. The Roleofthelnterleukin- 6 Family of Cytokinesin Inflammatory Arthritis and Bone Turnover. Arthritis \& Rheumatism , Vol. 48,No.5,Mapp1177-1189

Puttick ,M.P.(2001).Evalution of the patient with pain all over .Can Med Assoc J.164:223. 


\section{(QJPS)}

Vol. 24, No. 2, pp. $28-35$,Year2019

Shen, H., Xia, L., \& Lu, J . (2013). L nterleukin-4 in rheumatoid arthrit patients with interstitial lung disease: a pilot study. The Indian Journal Research, 138(6), 91

Study, C. (2014) . Association between Interleukin-6 Gene in Chinese Han Population : A, 1-5. https: //doi.org/10. 1038/srep05714. 